WRPS-49352-FP

Revision 0

\title{
AUTOMATED LEAK DETECTION OF BURIED TANKS USING GEOPHYSICAL METHODS AT THE HANFORD NUCLEAR SITE
}

Prepared for the U.S. Department of Energy

Assistant Secretary for Environmental Management

Contractor for the U.S. Department of Energy

Office of River Protection under Contract DE-AC27-08RV14800

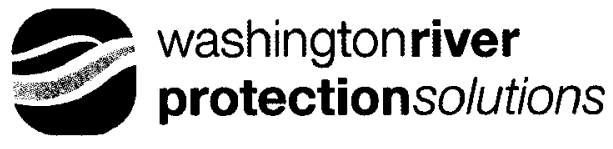

P.O. Box 850

Richland, Washington 99352 


\section{AUTOMATED LEAK DETECTION OF BURIED TANKS USING GEOPHYSICAL METHODS AT THE HANFORD NUCLEAR SITE}

S. Calendine

Hydrogeophysics, Inc., Tucson, AZ

M. T. Levitt

Hydrogeophysics, Inc., Richland, WA
J. B. Fink

D. F. Rucker

Hydrogeophysics, Inc., Tucson, AZ

J. S. Schofield

Washington River Protection Solutions

Date Published

March 2011

To Be Presented at

SAGEEP 2011

Environmental and Engineering Geophysics Society

Charleston, South Carolina

April 10, 2011

Prepared for the U.S. Department of Energy

Assistant Secretary for Environmental Management

Contractor for the U.S. Department of Energy

Office of River Protection under Contract DE-AC27-08RV14800

\section{2 washingtonriver protectionsolutions}

P.O. Box 850

Richland, Washington

Copyright License

By acceptance of this article, the publisher and/or recipient acknowledges the U.S. Government's right to retain a nonexclusive, royalty-free license in and to any copyright covering this paper.

$\frac{\text { A. Q A . Aardal }}{\text { Release Approval }} \frac{03 / 30 / 2011}{\text { Date }}$ 
LEGAL DISCLAMMER

This report was prepared as an account of work sponsored by an agency of the United States Government. Neither the United States Government nor any agency thereof, nor any of their employees, nor any of their contractors, subcontractors or their employees, makes any warranty, express or implied, or assumes any legal liability or responsibility for the accuracy, completeness, or any third party's use or the results of such use of any information, apparatus, product, or process disclosed, or represents that its use would not infringe privately owned rights. Reference herein to any specific commercial product, process, or service by trade name, trademark, manufacturer, or otherwise, does not necessarily constitute or imply its endorsement, recommendation, or favoring by the United States Government or any agency thereof or its contractors or subcontractors. The views and opinions of authors expressed herein do not necessarily state or reflect those of the United States Government or any agency thereof.

This document is available to the U.S. Department of Energy and its contractors, in paper from the Office of Scientific and Technical Information (OSTI). It is available for sale to the public from the National Technical Information Service (NTIS).

This report has been reproduced from the best available copy. Available in paper copy. 


\title{
AUTOMATED LEAK DETECTION OF BURIED TANKS USING GEOPHYSICAL METHODS AT THE HANFORD NUCLEAR SITE
}

\author{
Shawn Calendine, Hydrogeophysics, Inc., Tucson, AZ \\ Dale F. Rucker, Hydrogeophysics, Inc., Tucson, AZ \\ James B. Fink, Hydrogeophysics, Inc., Tucson, AZ \\ Marc T. Levitt, Hydrogeophysics, Inc., Richland, WA \\ John Schofield, Washington River Protection Solutions, LLC, Richland, WA
}

\begin{abstract}
At the Hanford Nuclear Site in Washington State, the Department of Energy oversees the containment, treatment, and retrieval of liquid high-level radioactive waste. Much of the waste is stored in single-shelled tanks (SSTs) built between 1943 and 1964. Currently, the waste is being retrieved from the SSTs and transferred into newer double-shelled tanks (DSTs) for temporary storage before final treatment. Monitoring the tanks during the retrieval process is critical to identifying leaks.

An electrically-based geophysics monitoring program for leak detection and monitoring (LDM) has been successfully deployed on several SSTs at the Hanford site since 2004. The monitoring program takes advantage of changes in contact resistance that will occur when conductive tank liquid leaks into the soil. During monitoring, electrical current is transmitted on a number of different electrode types (e.g., steel cased wells and surface electrodes) while voltages are measured on all other electrodes, including the tanks. Data acquisition hardware and software allow for continuous real-time monitoring of the received voltages and the leak assessment is conducted through a time-series data analysis. The specific hardware and software combination creates a highly sensitive method of leak detection, complementing existing drywell logging as a means to detect and quantify leaks. Working in an industrial environment such as the Hanford site presents many challenges for electrical monitoring: cathodic protection, grounded electrical infrastructure, lightning strikes, diurnal and seasonal temperature trends, and precipitation, all of which create a complex environment for leak detection. In this discussion we present examples of challenges and solutions to working in the tank farms of the Hanford site.
\end{abstract}

\section{Introduction}

The Department of Energy (DOE) manages approximately 53 million gallons of high level radioactive waste stored in 149 SSTs and 28 DSTs at Hanford (DOE, 2010). The tanks are situated in underground tank farms and contain waste composed of mixed waste streams from differing chemical separation processes. These highly complex waste combinations include large molar concentrations of ionic constituents, heavy metals, and radioactive isotopes (DOE, 2003). Sixty-seven of the SSTs have, or are suspected to have, leaked up to 1 million gallons of waste into the vadose zone (Gephart and Lundgren, 1998). Leaked waste presents a major environmental challenge, from both a management and risk perspective. An important step in avoiding further leaks from SSTs is to retrieve the waste and transfer it into more secure DSTs for temporary storage before final treatment.

Removing tank waste is an extremely difficult process and methods of waste retrieval differ, based primarily on tank integrity. If the tank is structurally sound, waste can be retrieved using high pressure jets and pumps. If, however, the tank's integrity is questionable or leaks occur during retrieval, a more expensive vacuum retrieval system may be required (Schofield, 2010a). Consequently, 
monitoring the subsurface and detecting leaks during retrieval is an important verification tool for assessing tank integrity.

Traditional leak detection methods on the SSTs include spectral gamma and neutron logging in the monitoring wells, which are drilled near tanks to varying depths. Well logging can be an insensitive tool because of its limited sample volume and time to conduct the measurement. If a leak occurs, tank waste must first move through the soil to within less than a meter of the monitoring wells before showing a positive leak result. This process could take days or even weeks before the leak is detected. In an effort to monitor tank integrity and minimize the length of time before potential leaks are caught, an electrical geophysics monitoring program has been tested and deployed on seven of the Hanford SSTs. The monitoring program takes advantage of changes in resistivity that occur when conductive liquid (sometimes greater than $5 \mathrm{M}$ nitrate, equivalent to $173 \mathrm{dS} / \mathrm{m}$ or $0.06 \mathrm{ohm}-\mathrm{m}$ ) leaks into a relatively resistive soil (approximately 1000-1500 ohm-m - see Rucker et al., 2009). During monitoring, current is transmitted and voltages are measured on steel cased wells, surface electrodes, and tanks. Data acquisition hardware and software allow for continuous real-time monitoring of the voltages, and leaks are discriminated through a time-series data analysis (i.e., statistically analyzing data acquired in a sequential order), creating a highly sensitive method for leak detection. This paper discusses the empirical validation of using time-series data analysis as a leak detection method, as well as some of the challenges that electrical monitoring must overcome when deployed in a long-term industrial environment.

\section{Background}

The Hanford Site is home to 177 underground storage tanks (Figure 1), which contain approximately $1.9 \times 10^{8} \mathrm{Ci}$ in $2 \times 10^{5} \mathrm{~m}^{3}$ of waste in viscous liquid, sludge, and salt cake waste forms (NRC, 2006). Two types of tanks are on the Hanford Site: single-shelled tanks and double-shelled tanks. The SSTs were in use from 1943 to 1980 and range in size from $208 \mathrm{~m}^{3}$ to $4400 \mathrm{~m}^{3}$. Of the 149 SSTs, 67 are listed as assumed leaking tanks, with approximately $3800 \mathrm{~m}^{3}$ of liquid released to the soil (Gephart and Lundgren, 1998). The DSTs contain an annulus around the inner tank which will contain any leakage from the primary tank wall. There are no known or assumed leaks from the DSTs, which have been in service since 1971. Both types of tanks store the waste generated during the reprocessing of irradiated uranium. This reprocessing was done in five chemical plants, scattered around the 200 areas of Hanford (Corbin et al., 2005).

The DOE is currently managing the waste in the SSTs by moving it to safer DSTs and eventually into a solid waste form. Waste retrieval is a difficult process due to the engineering problems posed by the varied tank waste forms and associated health and safety risks for workers. In support of waste retrieval operations, DOE has agreed to conduct leak detection, monitoring, and mitigation to ensure that additional leaks to the vadose zone are minimized. To help the DOE with the development of a monitoring program, the Pacific Northwest National Laboratory (PNNL) established the Vadose Zone Transport Field Studies (VZTFS - Ward and Gee, 2000; 2001) and Tank Leak Detection Demonstrations (Barnett et al., 2001; 2002) to examine potential characterization and monitoring technologies that could be deployed in the tank farms and utilize, to the extent possible, existing infrastructure (e.g., more than 1,300 steel-cased wells). The list of candidates for initial testing in an injection experiment included electrical resistivity tomography (ERT), high resolution resistivity - steel cased resistivity tomography (HRR-SCRT, which was subsequently referred to as high resolution resistivity-leak detection monitoring or HRR-LDM), cross-borehole radar, cross-borehole seismic, cross-borehole electromagnetic induction, and subsurface airflow and extraction. Of the geophysical methods, it was 
found that those based on direct current electrical resistivity, i.e., ERT and HRR-LDM, were better suited for monitoring. Additional testing at a three-quarter scale mock tank test facility confirmed that a time-series based monitoring, such as HRR-LDM, was capable of highly accurate and timely leak detection.

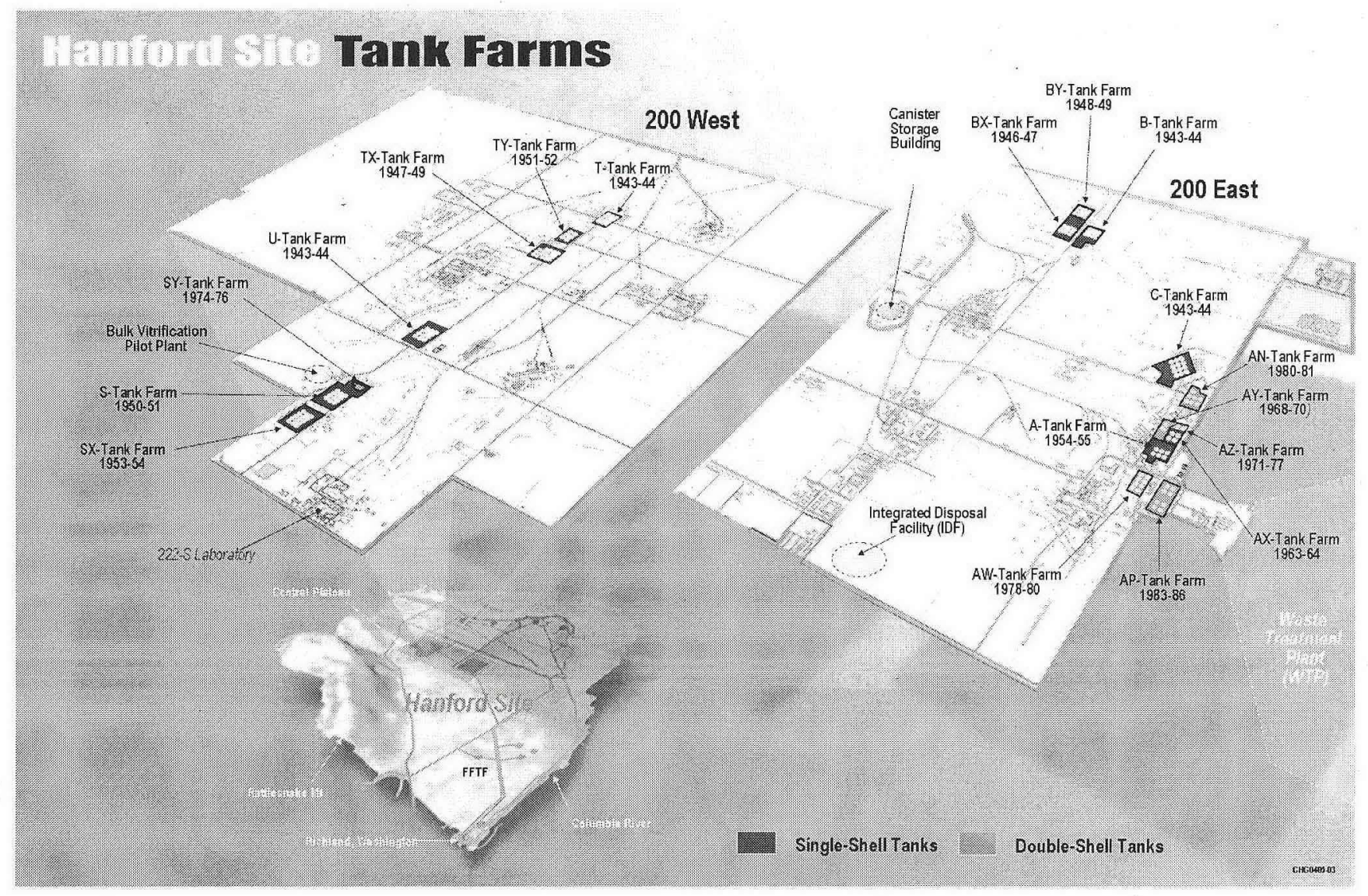

Figure 1: Tank farms on the Hanford Site.

Initial deployment of the HRR-LDM technology in a tank farm occurred in 2004 on the S-102 tank in the $\mathrm{S}$ tank farm. Figure 2 shows the general timeline of development and deployment of the HRR-LDM system at Hanford. Monitoring occurred for approximately 20 months before an in-farm leak demonstration test was conducted, which was meant to demonstrate how well the technology worked in a tank farm setting. Factors such as complex electrical fields present in a tank farm related to cathodic protection or grounded electrical infrastructure pose challenges to accurately assessing a leak, as does external environmental factors such as lightning strikes, diurnal and seasonal temperature trends, and precipitation. 


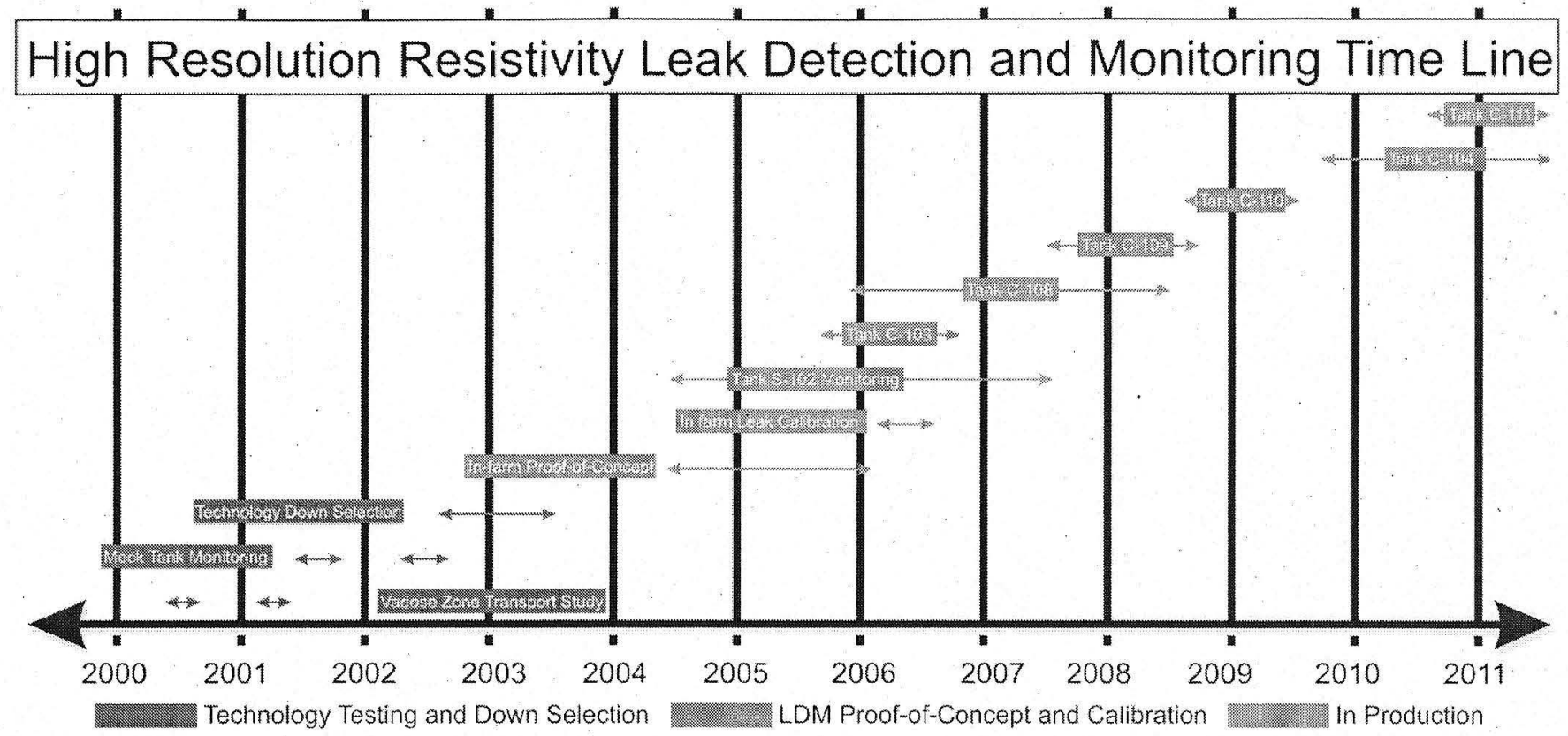

Figure 2: Timeline of LDM development and deployment at Hanford

After the demonstration test, monitoring of the S-102 tank occurred for another year. In the meantime, a second data acquisition system was built for the $\mathrm{C}$ tank farm. The $\mathrm{C}$ tank farm is planned to be the first to be closed and capped and an accelerated schedule was developed to retrieve waste from all of the C-farm tanks, starting with C-103. Since 2005, waste has been retrieved from several tanks, seven of which utilized HRR-LDM.

\section{Proof-of-Concept}

The Groundwater/Vadose Zone Integration Project Science and Technology program was formed in FY1999 in an effort to understand and limit the ambiguity related with the vadose zone transport structure within the near subsurface. An integral component of the program was to implement an array of field studies to address the complex and challenging cleanup activities that would need to occur in the vadose zone due to over 40 years of planned and unplanned releases. Previous to this project, geophysical characterization and monitoring technologies were not as rigorous, resulting in inadequate knowledge of contaminant migration and tank waste leakage through the Hanford soils (Rucker et al., 2008).

The Vadose Zone Transport Field Study (VZTFS) was conceived as part of the integration program to address major uncertainties related to the movement, distribution, and transport of source contaminants within the Hanford tank farms (Ward and Gee, 2001). The VZTFS also conducted field tests in an effort to develop leak detection methods. Major themes of the program were efficiency and cost-effectiveness. Therefore, incorporating these themes by employing existing infrastructure to support characterization and monitoring techniques in tank farms was critical to the success of any project. To this end, tests were conducted with electrical-based geophysics at the Sisson and Lu (S\&L) site, Mock Tank Site, and within the S tank farm. 


\section{Sisson and Lu}

Two infiltration tests were conducted in 2000 and 2001 at the S\&L site (Gee and Ward, 2001). Injections for the first test began in May 2000, with an initial $4000 \mathrm{~L}$ of water into a well near H-2 at 5 $\mathrm{m}$ below surface (Figure 3A); the injection occurred over a 6-hour period. Similarly, $4000 \mathrm{~L}$ of water was injected in four subsequent injections. During the injection period, neutron logging took place in 32 steel-cased wells $(0.15 \mathrm{~cm}$ diameter, $18 \mathrm{~m}$ long) within a day following each of the first four injections, and three additional readings of each well were completed within two months after injection (Ye et al., 2007). The second infiltration test was conducted using a hypersaline tank waste simulant (36\% sodium thiosulfate with an approximate resistivity of $0.08 \mathrm{ohm}-\mathrm{m}$ ) in March, and April, 2001. Approximately $13,200 \mathrm{~L}$ were injected over 10 leak events, with three water "chasers" $(11,300 \mathrm{~L})$ following in May 2001.

Electrical resistivity data were acquired on a number of different configurations using steel-cased wells, the injection well, bottom-hole electrodes placed at the bottom of the wells that were electrically insulated from the steel, and an array of surface electrodes. A McOHM-21 (Oyo Corp) was used for the data acquisition over the two-month injection experiment. Figure $3 \mathrm{~B}$ shows the time log of injections and electrical conductivity of the solution for the second series of injections. The electrical potential time series is also shown, which was acquired on a well near the injection point during electrical current transmission on an electrode in the PVC injection well. All data were acquired with the pole-pole array, where poles for each transmission and receiving pair were effectively at infinity. The data were acquired during three separate trips to the field site and intermittency of data acquisition was due to shared resources with other technologies. The voltage potential shows 1) a large change at the onset of the injection, and 2) a sustained decrease in voltage through the injection as a result of the subsurface becoming more conductive.
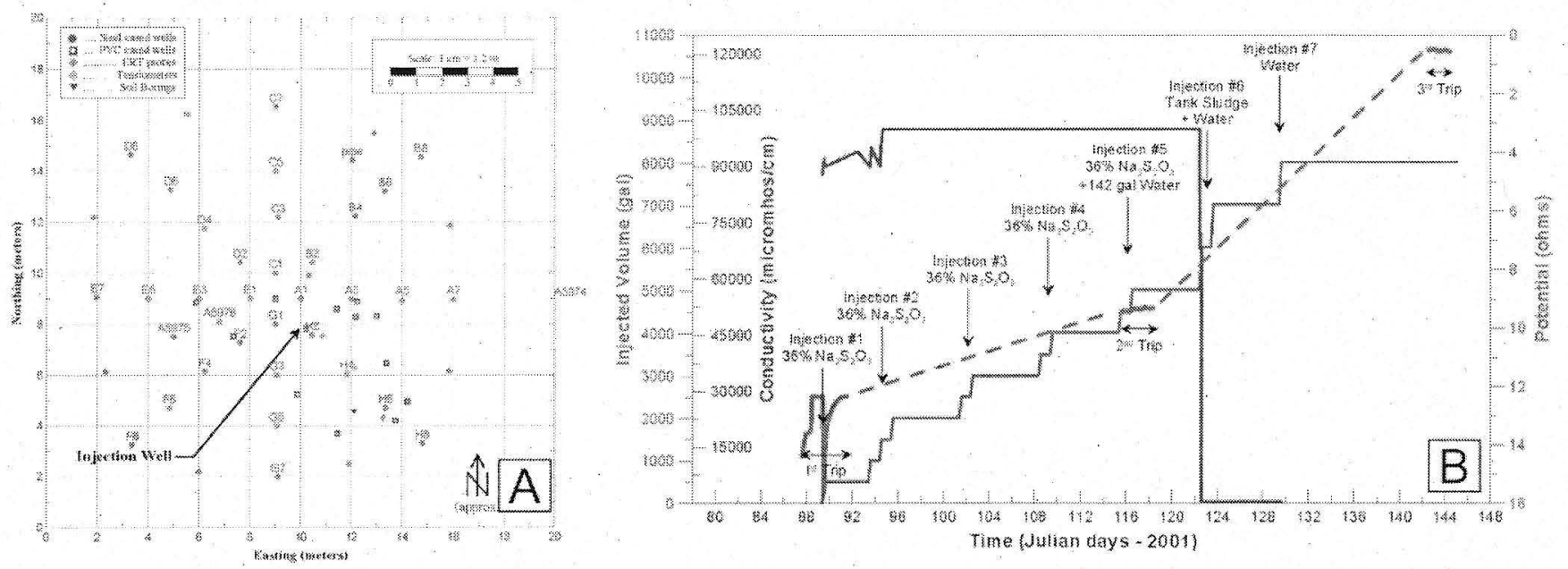

Figure 3: Sisson and Lu Site. A) layout of steel-cased monitoring wells and injection well. B) Cumulative injected volume, conductivity of injected solution, and voltage potential on a steel cased well during the second series of injections with sodium thiosulfate.

\section{Mock Tank}

A more complex tank leak detection field study was conducted at the Mock Tank Site in the 200 East Area of the Hanford Site. The 15.24-m (50-ft)-diameter Mock Tank structure was constructed in 1994-1995 for testing the applicability and effectiveness of ERT imaging of simulated fluid leaks beneath a steel-lined tank. In August 2001, five leak sequences were performed and a total of 15,100 L 
of solution was released during the two-week test period. Electrical monitoring of background and noise conditions was conducted before the simulated leak test period. Two of the five leaks were "blind" in that none of the geophysical operators knew the solution release volumes/flow rates (Barnett et al., 2002). Figure 4A shows the general layout of the mock tank site, with the injection points located inside the mock tank and the monitoring wells on the periphery of the tank. A fourth steel-cased well and a steel sheet pile were added later for a second test, as described below. Figure 4B shows a conceptual diagram of the geophysical arrangement for leak detection, using a time-lapse mise-a-la-masse (i.e., excitation of source) methodology of energizing the leak port.

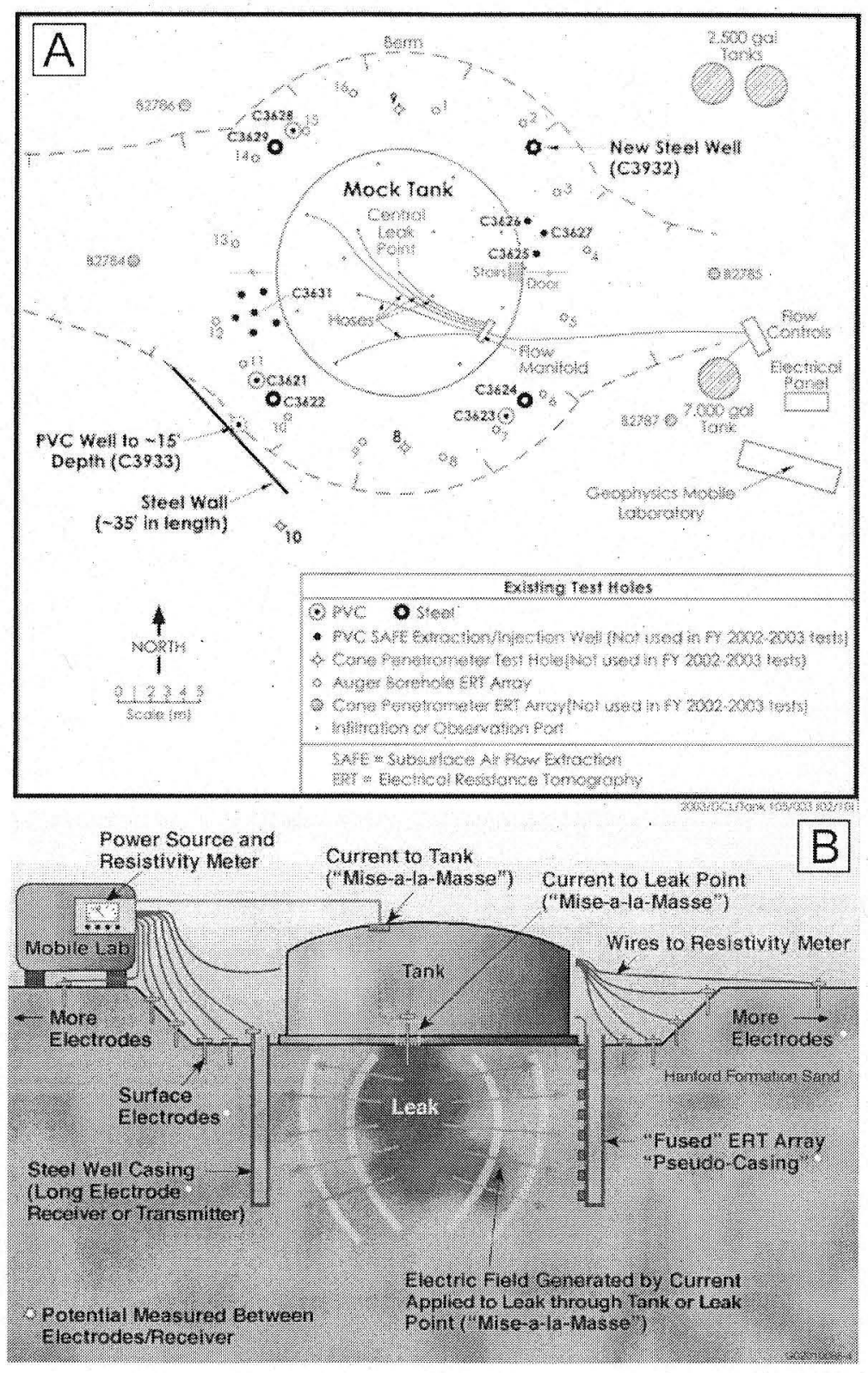

Figure 4: Mock Tank Site. A) Layout of tank relative to steel wells. B) Schematic of the measurement strategy at the Mock Tank. 
A second Mock Tank injection experiment was conducted from July through November of 2002. During this 110-day blind test designed around EPA protocol performance evaluation (PE) requirements, thirteen releases of $38 \mathrm{wt} \%$ sodium thiosulfate solution totaling $\sim 53,000 \mathrm{~L}$ were injected into the soil beneath the tank. Additionally, four simulated rain events and one flood event were conducted to test changing environmental conditions. The entire test was monitored remotely through an internet connection.
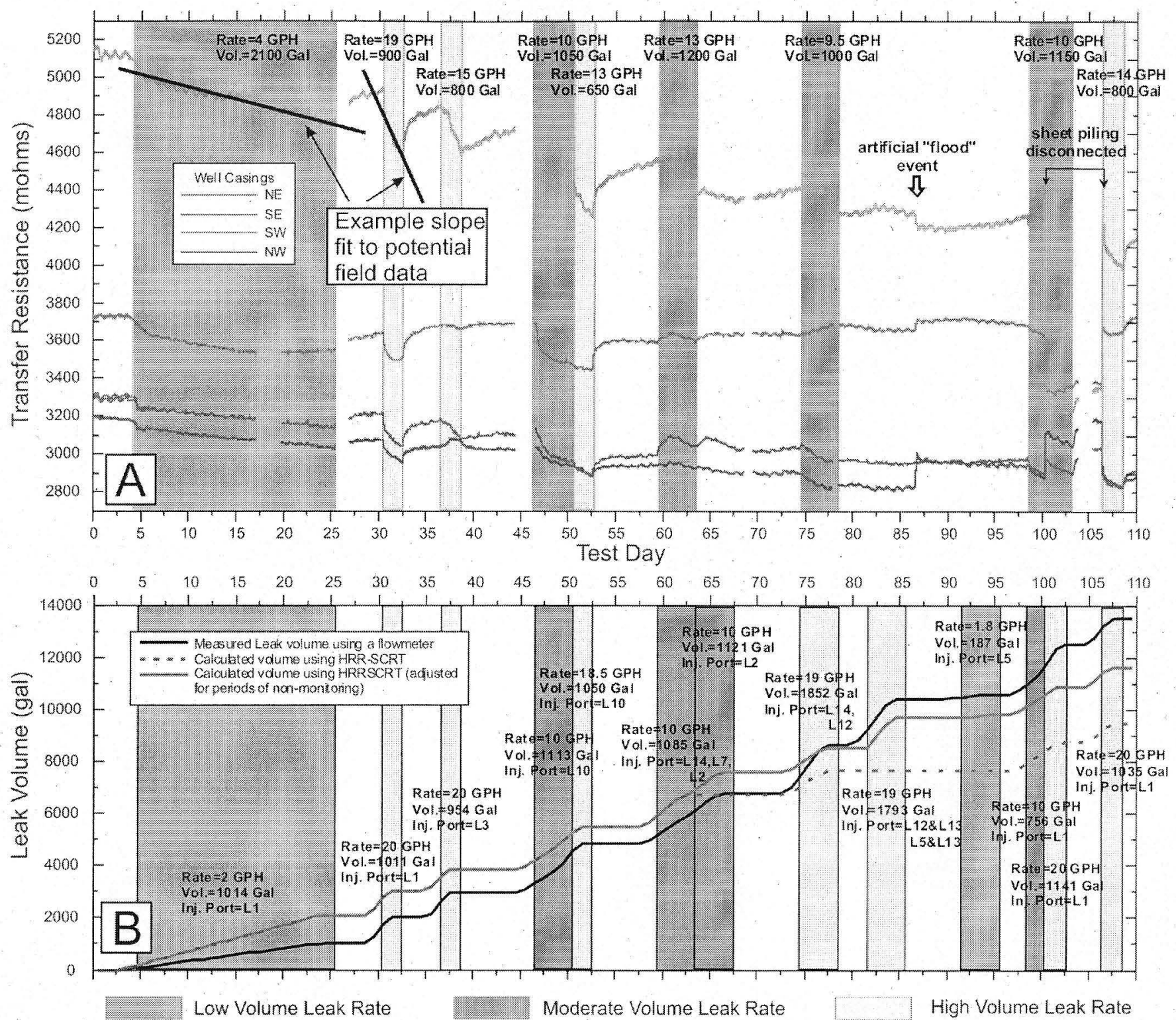

Figure 5: Mock Tank Data from the second injection experiment in 2002. A) Voltage potential (normalized to current) for the four steel cased wells during current injection on the leak source. Regression is used to estimate leak rates and volumes. Leak intervals for leaks detected using HRRLDM are shown using colored bars. B) Actual leak rates and volume vs. calculated leak volume from using HRR-LDM. The thirteen total leak events are shown using colored bars indicating a relative leak rate. 
For the first Mock Tank study, a SuperSting R8 (AGI, Austin, TX) was used for the electrical measurements. The second injection experiment used the GDP-32 II (Zonge Engineering, Tucson, AZ). The second Mock Tank experiment allowed a near continuous time-series dataset to be acquired at a sampling rate that showed detailed temporal changes of the subsurface. Figure 5A shows the potential data measured on the four wells surrounding the mock tank, along with leak intervals, rates and volumes estimated using HRR-LDM. Figure 5B shows the actual leak injection periods, rates, and volumes, versus the HRR-SCRT estimated leak volume (figures from Barnett et al., 2003). The potential data demonstrate a relationship between the slope of the potential change and the injection rate, where steep slopes correlate to high injection rates. For this analysis, nine of the 13 leaks were identified using the HRR-LDM technology and estimates of the leak rate and volume were very close to the actual measurements.

\section{S102 Leak Injection Test}

Deployment of a full HRR-LDM data acquisition system that met the rigors of a nuclear tank farm environment, including quality assurance and safety, commenced in May 2004. The system was set up around tank S102, using 15 steel-cased wells, 8 surface electrodes, and a steel riser through the tank that was in contact with the tank contents. Figure 6 shows the layout of the system. In January 2006, a leak injection experiment was conducted by converting one of the monitoring wells into an injection well (designated 40-02-10, located at the 10 o'clock position around the tank). The well conversion was achieved by perforating from 15 to $33 \mathrm{~m}$ below ground surface and plugging the well below the perforated zone. The perforated zone was designed to simulate a leak from the tank bottom. Test simulated waste consisted of a $25 \%$ (by volume, or $250,000 \mathrm{ppm}$ ) sodium thiosulfate pentahydrate solution with a specific gravity of approximately 1.138 at a temperature of 23.1 degrees Celsius. The simulant had electrical properties similar to the radioactive waste stored in underground tanks, which was estimated to be approximately $0.08 \mathrm{ohm}-\mathrm{m}$ (Rucker et al., 2011).
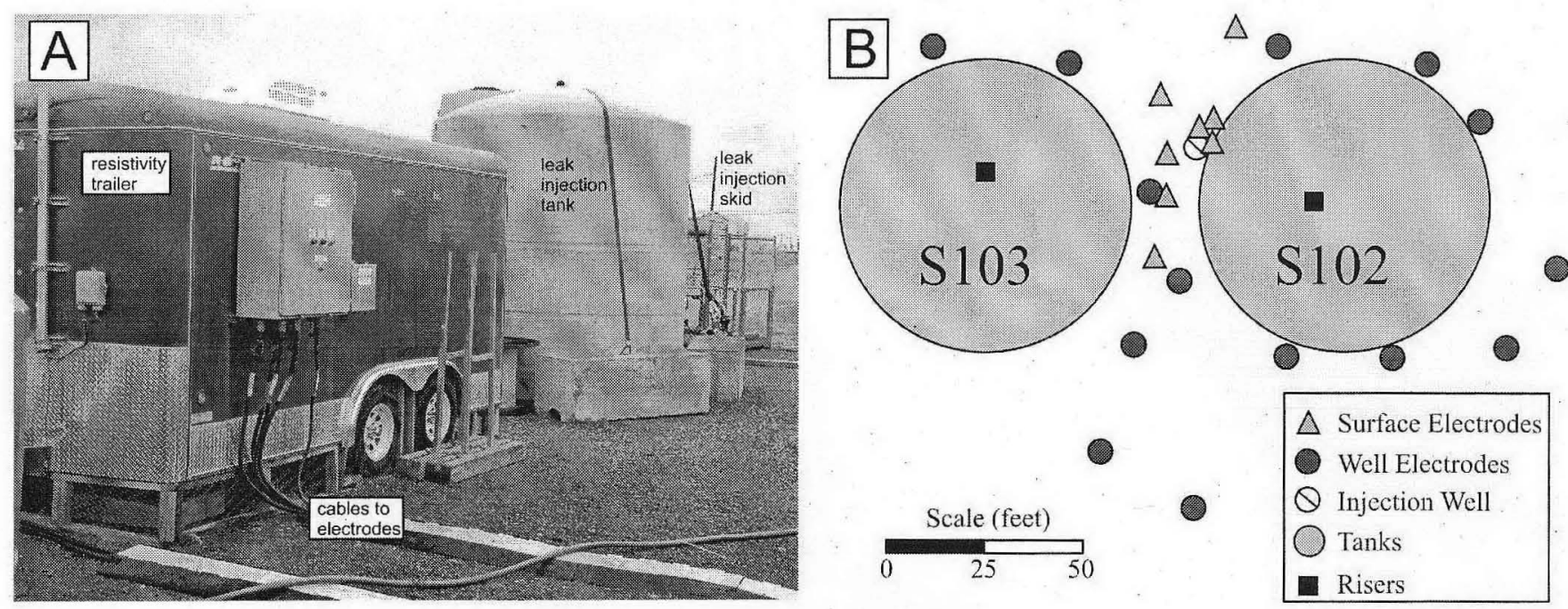

Figure 6: A) Environmentally controlled trailer housing the HRR-LDM data acquisition equipment and electronics. Photo taken during the leak injection test at S-102. B) Layout of the HRR-LDM electrodes around tank S-102 and the injection well.

The leak injection test included ten leak events over four months. Data were collected in near real time and analyzed on a once daily basis during the injection leak test period to identify data trends 
indicative of a leak. An assessment was completed at the end of each leak event to evaluate the performance of the leak detection technology. The results indicated that eight of the ten leaks were detected by the system. Statistical analysis of test data also indicated the system was capable of detecting a leak of approximately 2100 gallons $95 \%$ of the time, for the test geometry and soil conditions present. It is believed the system threshold is significantly below this statistical value.

\section{Long-Term Monitoring}

Current HRR-LDM technology consists of a data acquisition system (DAS) housed in a small trailer sited adjacent to the tank farm (Figure 6A). Cables run from the DAS to wells around the target waste tank, surface electrodes, and to a tank riser. The DAS controls switching for the various transmitting and receiving electrode pairs. A complete data set contains a data sequence where each electrode acts as both a transmitter and a receiver, with the exception of the tank which never acts as a transmitter due to tank safety concerns. Time to acquire a single data set is dependent upon the number of electrodes and tank combinations. A single data set containing one tank can take as little as 12 minutes, while a data set containing multiple tanks can take over 20 minutes. A complete data set is composed of the contact resistance, a transmitting current value for each well, received voltage, a calculated apparent resistivity value, an estimate of measurement error, and self potential. An example data set for the C-104 tank monitoring is shown in Figure 7, where the transmitting well is 30-07-05 (north east of the tank), and the potentials are recorded on several other electrodes, both the wells and the tank.

Each data type, depending on the electrode, provides critical information on resistivity changes occurring around the tank. As the data are acquired and processed, each electrode pair is graphed and trends are evaluated for leaks. When a trend differs significantly from expected baseline conditions, electrical characteristics of the monitored environment have changed. However, this does not automatically indicate a leak from the tank. Thus, the system does not provide a binary yes or no answer for leak detection from potential data alone (Schofield, 2010). The different data types must first be analyzed relative to other competing factors. If no suitable justification can be determined for the change in trend than a leak potential assessment process is entered.

Factors that potentially create false positives in leak detection analysis fall in one of three categories: environmental, anthropogenic, or system malfunctions. Environmental challenges such as diurnal and seasonal temperature changes, local precipitation, and lightning can cause fluctuations in recorded data. For example, an inverse relationship exists between temperature and soil resistivity values. As the ambient temperatures increase the near surface soil resistivity values decrease. The consequences of diurnal soil heating were observed during the Mock Tank experiment, and their effects can be seen in Figure 5A. Diurnal temperature effects are usually subtle features at amplitudes less than an actual leak response. Precipitation, on the other hand, can create more noticeable changes with amplitudes that warrant further analysis. This is most noticeable when using surface electrodes that only penetrate a short distance into the ground compared to the drywells which usually go down 100 feet or more. A major rain event or snow melt can change near surface soil characteristics around the well head, producing questionable changes in data and creating a need for potential leak analysis. Figure 7 shows how several of these environmental factors can manifest in the data. Finally, lightning can cause serious harm to the DAS electrical components if the strike hits within the footprint of the HRR-LDM array. In preparation for an outage, secondary data acquisitions systems or spare electrical parts are required to be readily available to return the DAS to operational mode quickly. Three lightning strike 
events have taken place that have damaged equipment while HRR-LDM arrays have been active on the Hanford site.

In an industrial environment such as Hanford, there are many anthropogenic causes for changes in the electric field around tanks. Grounded electrical support systems such as pumps, evaporators, cathodic protection, and competing HRR-LDM systems operating in adjacent tank farms can cause temporal fluctuations in electrical data. Communication with tank farm operators is critical for determining if a change is caused by the industrial environment or if the change is a potential leak anomaly. Fortunately, anthropogenically-related electrical changes in a tank farm generally cause a uniform disturbance across all transmitting and receiving data pairs. The difference in cathodic protection in Figure 7, for example, shows higher amplitude noise in all measurement pairs compared to the brief time in which it was shut off.

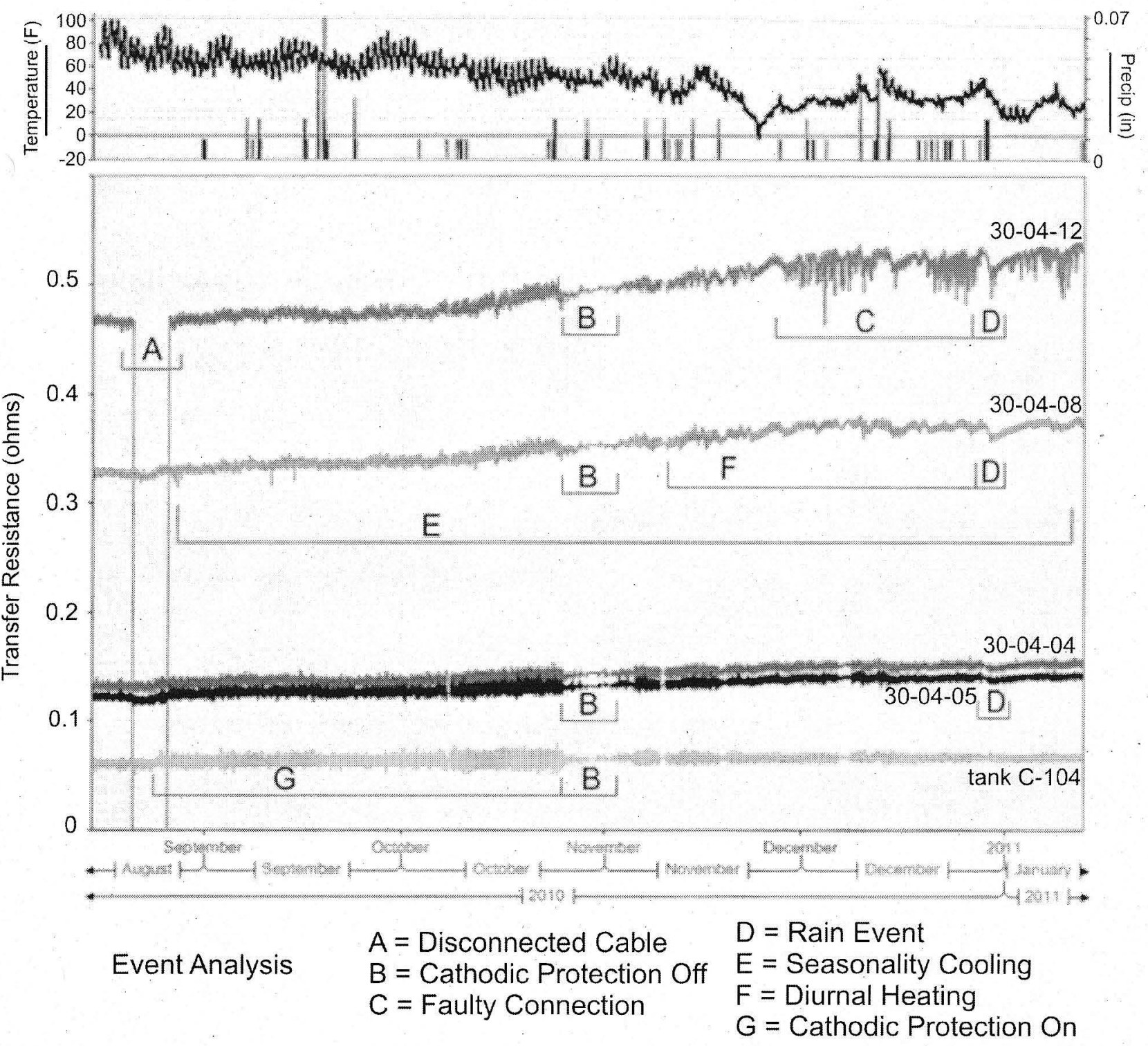

Figure 7: Event analysis for monitoring tank C-104 during the months from August 2010 to January 2011. Voltages were measured on a number of different electrodes during current transmission on well 30-07-05. No leaks were detected with the HRR-LDM system during this time. 
To address the potential for system malfunctions, a multilevel alarm system was built into the DAS. If the DAS cannot transmit current to a well or tank because of a break in a connecting cable, an "open circuit" alarm is produced and sent via email and text message to the LDM operator. Power disruptions, extreme thermal changes, and physical entry into the DAS trailer also produce alarms alerting operators. When an operator receives an alarm, prompt investigation usually reveals obvious problems that can be addressed remotely through internet connections or physically by dispatching engineers to the DAS trailer.

\section{System Automation}

In 2007 the LDM data processing component was automated through the addition of AutoPro and a web-based analysis software called AutoView. The automation reduces or eliminates operator error by adding consistency in the processing and evaluation methods (Schofield, 2010b). Additionally, automation minimizes manual review time and increases the speed at which the operator has access to data and other system information. Each monitoring enhancement--automation, system alarms, and instant access--greatly decreases potential operator errors and time delays in response to system malfunctions, thereby increasing system performance. However, occasional anomalies are still expected and a final decision as to whether a potential leak exists is based on an operator's knowledge and experience.

\section{Conclusions}

An electrical-based leak detection monitoring system has been deployed at the Hanford Site since 2004 to monitor tank waste retrieval. The system relies on time series analysis of voltage potential, where short-term trends in the voltage can reveal both leak onset and relative leak rates. The system has undergone vigorous testing at several facilities with varying degrees of complexity, including the Sisson and Lu site, Mock Tank site, and at the S tank farm. The S Farm demonstration test showed the system of acquisition and analysis to be sensitive to leaks of at least 2100 gallons $95 \%$ of the time, for the test geometry and soil conditions present. It is believed the system threshold is significantly below this statistical value.

Long-term deployment of a geophysically-based technology can be challenging, especially in industrial settings such as a nuclear waste tank farm. Factors such as those derived from environmental conditions, anthropogenic changes, and system malfunctions can affect data quality, leak interpretation, and system up-time. To overcome these challenges, the HRR LDM data acquisition system has been designed with a number of alarms that can warn operators sufficiently early so that data loss can be minimized. Additionally, replacement parts are always available as needed for continuous equipment operation. Lastly, new automation features have given operators valuable time to focus on more important tasks such as data interpretation by reducing time needed to complete routine data processing tasks.

\section{References}

Barnett, D.B., G.W. Gee, and M.D. Sweeney, 2001, Test Plan for the Demonstration of Geophysical Techniques for Single-Shell Tank Leak Detection at the Hanford Mock Tank Site-Fiscal Year 2001, PNNL-13598, Pacific Northwest National Laboratory, Richland, Washington. 
Barnett, D.B., G.W. Gee, and M.D. Sweeney, 2002, Results of Tank-Leak Detection Demonstration Using Geophysical Techniques at the Hanford Mock Tank Site-Fiscal Year 2001. PNNL13818, Pacific Northwest National Laboratory, Richland, Washington.

Barnett, D.B., G.W. Gee, M.D. Sweeney, M.D. Johnson, V.F. Medina, D.P. Mendoza, B.G. Fritz, F. Khan, W.D. Daily, J.B. Fink, M.T. Levitt, and A.M. Binley, 2003. Results of Performance Evaluation Testing of Electrical Leak-Detection Methods at the Hanford Mock Tank Site--FY 2002-2003. PNNL-14192, Pacific Northwest National Laboratory, Richland, WA.

Corbin, R.A., B.C. Simpson, M.J. Anderson, W.F. Danielson III, J.G. Field, T.E. Jones, and C.T. Kincaid, 2005. Hanford Soil Inventory Model, Rev. 1. PNNL-15367, Pacific Northwest National Laboratory, Richland, WA.

Department of Energy 2003, Hanford Cultural and Historic Resources Program, Hanford Site Historic District, History of the Plutonium Production Facilities 1943-1990, DOE/RL-97-1047 Battelle Press. Columbus Richland.

Department of Energy 2010. Hanford Site Cleanup Completion Framework, DOE/RL-2009-10. U.S. DOE Richland Operations Office. Richland, WA.

Gephart, R.E, and R.E Lundgren, 1998. Hanford Tank Cleanup: A Guide to Understanding the Technical Issues. Battelle Press, Columbus, $\mathrm{OH}$.

National Research Council, 2006. Tank Waste Retrieval, Processing, and On-site Disposal at Three Department of Energy Sites: Final Report. National Academies Press. Washington DC. 214p.

Rucker, D.F., M.T. Levitt, D.A. Myers, and C. Henderson, 2008. Development of an Electrical Resistivity Imaging Program for Subsurface Characterization at Hanford. WM2008 Conference, February $24-28,2008$, Phoenix, AZ.

Rucker, D.F., M.T. Levitt, and W.J. Greenwood, 2009. Three-dimensional electrical resistivity model of a nuclear waste disposal site. Journal of Applied Geophysics 69:150-164.

Rucker, D.F., J.B. Fink, and M.H. Loke, 2011. Environmental monitoring of leaks using time lapsed long electrode electrical resistivity. Journal of Applied Geophysics (accepted).

Schofield, J.S., 2010a. Single-Shell Tank Waste Retrieval Plan, RPP-Plan-40145, Rev 1, Washington River Protection Solutions LLC, Richland, Washington.

Schofield, J.S., 2010b. High Resolution Resistivity Leak Detection Data Processing and Evaluation Methods and Requirements, RPP-32477, Rev 1, Washington River Protection Solutions LLC, Richland, Washington.

Ward, A.L., and G.W. Gee, 2000. Vadose Zone Transport Field Study: Detailed Test Plan for Simulated Leak Tests, PNNL-13263, Pacific Northwest National Laboratory, Richland, Washington.

Ward, A.L. and G.W. Gee, 2001, Vadose Zone Transport Field Study: FY2001 Test Plan, PNNL-13451, Rev. 1, Pacific Northwest National Laboratory, Richland, Washington.

Ye, M., R. Khaleel, and T.-C. J. Yeh, 2005. Stochastic analysis of moisture plume dynamics of a field injection experiment. Water Resources. Research, 41:W03013. 